\title{
Choosing between Innovation and Imitation in a Model of International Rivalry
}

\author{
Kenji Fujiwara Koji Shimomura \\ Kwansei Gakuin University Kobe University \\ Kar-yiu Wong \\ University of Washington
}

November 13, 2006 


\begin{abstract}
This paper constructs a model of international rivalry to examine the competition in terms of technology and output between firms in two trading countries. We analyze how the less efficient firm chooses endogenously between innovation and imitation, and how its decision may affect the market equilibrium and profits of the firms. Conditions under which the less efficient firm is able to catch up or to surpass the technology of the advanced firm have been derived. The implications of removing the endogeneity of this decision of the less efficient firms are also examined.
\end{abstract}




\section{Introduction}

Globalization in recent years has greatly enhanced trade and technology diffusion among countries. This phenomenon has brought to government planners and economists many contentious issues. ${ }^{1}$ Among these issues is the one about international transfer of technology and the appropriate responses of the governments. With firms producing similar products in various trading countries, the improvement of technologies and possible international spillover of technologies would affect the competitiveness of these firms and the welfare of their countries. Governments and economists are thus eager to find out the right policies to improve the welfare of their own countries.

There is a large literature on the output-technology competition among firms in different countries. In terms of how firms compete in technology, papers in this literature can be divided into two categories: those that assume that all firms are choosing innovation optimally, and those that examine the competition between some firms that innovate and some firms (usually in other countries) that imitate.

One of the earlier papers that examines how international rival firms choose innovation is Spencer and Brander (1983). They also examine the roles of R\&D subsidies provided by one or both governments. Bagwell and Staiger $(1992,1994)$ investigate the robustness of such $R \& D$ subsidies in the presence of uncertainty, and argue that Spencer and Brander's (1983) argument for the strategic R\&D subsidy is not confined to a deterministic environment.

The innovation-imitation relations among firms have drawn more attention in the literature. For example, Segerstrom (1991) constructs a model

\footnotetext{
${ }^{1}$ Bhagwati (2004) makes an extensive and stimulating argument on globalization and welfare in the modern world.
} 
of economic growth in which some firms innovate to improve the quality of their product and some others imitate. Using a dynamic North-South model, Grossman and Helpman (1991) conclude that the North's R\&D activity is enhanced by the existence of the imitating South. In a similar framework, Helpman (1993) discusses the effects of enforcement of intellectual property rights. $^{2}$ Dinopoulos and Syropoulos (1998), taking account of the more efficient firm's imitation-blocking and the less efficient firm's appropriating activities, identify the conditions under which these 'redistributive' expenditures become positive. Dinopoulos et al. (2006) construct a Schumpeterian growth model of international trade and examine the effect of patent protection on the rate of innovation and imitation. Liao and Wong (2004), also assuming an innovation-imitation relation between developed countries and developing countries, examine to what extent the governments of developing countries would be willing to provide intellectual property rights protection and investigate the roles and the shortcomings of the TRIPS agreement.

These papers all start with the presumption that less efficient firms are given a particular channel through which they improve their technologies: either innovation or imitation. This seems to be a serious limitation in many cases because in more general models the less efficient firms should have the option of choosing the optimal way to improve their technologies. In other words, the choice between innovation and imitation should be given to these firms, instead of arbitrarily assigning a technology-improving path to them. To see how serious this limitation is, we just have to note that many firms in many emerging countries started by imitating the technologies of firms in developed countries, but over time switched to developing their own technologies. In such a process, they gradually caught up with the

\footnotetext{
${ }^{2}$ Helpman's (1993) model is recently extended and reexamined by Mondal and Gupta (2006).
} 
advanced technologies and even surpassed them. The switch from imitation to innovation is missing in the papers mentioned above.

One very early exception that endogenizes the decision of a firm between innovation and imitation is Shimomura and Wong (2001). Using a dynamic model of international rivalry, they examine the conditions for innovation and imitation by a less efficient firm, and investigate the circumstances under which the firm will choose to innovate or imitate. They show some interesting cases in which the less efficient firm chooses imitation initially but switches to innovation in the future. There are also cases presented in the paper in which the less efficient firm always chooses to imitate and never finds it profitable to innovate.

The purpose of this chapter is to offer another framework to examine the choice between innovation and imitation. ${ }^{3}$ Using a simple model of oligopolistic competition, we endogenize the less efficient firm's choice between innovation and imitation. We also investigate the conditions under which the less efficient firm chooses to catch up or surpass the advanced firm in terms of technology. This model and the analysis allow us to answer one question: If the less efficient firm will choose to innovate, what happens if the firm is assumed to imitate instead? This question is important because many papers just assume the innovation-imitation relations between two firms without checking whether the less efficient may in fact choose to innovate instead, if it is allowed to. If one assumes that the less efficient imitates but it prefers to innovate, what kind of error may one commit?

The rest of this chapter is organized as follows. Section 2 describes the model with two firms, one in each country. The firms, with different ini-

\footnotetext{
${ }^{3}$ The present framework is based on that in Shimomura and Wong (2001), except that it is a static one. This allows us to investigate the rivalry between and strategies of the firms in more detail.
} 
tial technology levels, attempt to improve their technology and use the new technology to produce a homogeneous product to be exported to the rest of the world. Section 3 examines the case in which both firms innovate before producing the product. Thus they compete directly in terms of technology and output. Section 4 turns to the case in which the more efficient firm innovates while the other one imitates. Section 5 examines the conditions for catching up and surpassing in the innovation-innovation case and in the innovation-imitation case. Section 6 endogenizes the innovation/imitation decision of the initially less efficient firm. Section 7 concludes.

\section{The Model}

Consider a model consisting of three countries labelled Home, Foreign, and ROW (the Rest of the World). Both Home and Foreign has a firm producing a homogeneous product, which is exported to ROW. There is no demand for the product in Home or Foreign, and the demand in ROW can be represented by a linear function

$$
p=a-q,
$$

where $p$ is the market price and $q$ the demand. The value of $a$ is positive and sufficiently large so that the market can support both the Home firm and the Foreign firm.

Initially the Home firm is able to produce the product using a marginal cost, $c_{0}$, which is independent of the output level. The corresponding initial marginal cost of the Foreign firm is $c_{0}^{*}$. ${ }^{4}$ We assume that initially the Home firm has a more advanced technology; i.e.,

Assumption 1. $c_{0}<c_{0}^{*}$.

\footnotetext{
${ }^{4}$ Unless stated otherwise, the variables of Foreign are distinguished by asterisks. Without loss of generality, we assume that the fixed costs of the firms are negligible.
} 
If we denote the output of the Home (Foreign) firm by $x\left(x^{*}\right)$, which is the same as the export of the product by the country, in equilibrium we have

$$
q=x+x^{*} .
$$

The two firms compete in terms of technology and output. In terms of output, they compete in a Cournot-Nash fashion. In terms of technology, both of them are able to improve their technology, or to reduce their marginal costs, through one of the two channels: innovation and imitation.

Innovation requires the intentional expenditure on resources, which results in the improvement of technology. More specifically, we assume that after spending an amount of $e g^{2} / 2, e>0\left(e^{*} g^{* 2} / 2, e^{*}>0\right)$, the Home (Foreign) firm is able to reduce its marginal cost by an amount of $g\left(g^{*}\right)$. Variable $e\left(e^{*}\right)$ can be interpreted as the cost of innovation. ${ }^{5}$

Define two variables:

$$
\begin{aligned}
z & =\frac{a-c_{0}^{*}}{a-2 c_{0}^{*}+c_{0}} \\
z^{*} & =\frac{a-c_{0}^{*}}{a-2 c_{0}^{*}+c_{0}} .
\end{aligned}
$$

Since $c_{0}^{*}>c_{0}$, equations (3) imply that $z>1$ and $1>z^{*}>0$. To guarantee that if a firm chooses to innovate, the level of innovation is positive, we make the following assumption:

Assumption 2. $e>z, e^{*}>z^{*}$.

If both firms choose to innovate, their new marginal costs become, re-

\footnotetext{
${ }^{5}$ Variable $e$ is interpreted as the cost of innovation because $e g^{2} / 2$ is the cost the home firm has to pay in order to reduce its marginal cost by $g$. As will be shown later, an increase in $e$ will lower the firm's output, level of innovation, and profit.
} 
spectively,

$$
\begin{aligned}
c_{1} & =c_{0}-g \\
c_{1}^{*} & =c_{0}^{*}-g^{*} .
\end{aligned}
$$

Imitation exists when a firm chooses to learn from the other firm. For example, if the Foreign firm imitates, its new marginal cost becomes

$$
c_{1}^{*}=c_{0}^{*}-\theta\left(c_{0}^{*}-c_{0}\right),
$$

where $\theta \in(0,1) .{ }^{6}$ We assume that imitation requires no costs.

Since initially the Home firm has a lower marginal cost, it has nothing to learn from the Foreign firm. This means that for the Home firm, imitation is the same as inaction, spending zero resources on innovation and thus getting zero innovation. We can thus reduce the present analysis to the following two cases: (A) Both firms innovate; and (B) The Home firm innovates while the Foreign firm imitates. These two cases are analyzed below.

\section{Case (A): Foreign Firm Innovating}

In this case, both firms innovate. Denote the profits of the Home and Foreign firms by $\Pi^{v}$ and $\Pi^{* v}$, respectively, where superscript " $v$ " denotes the variables in this case. We have

$$
\begin{aligned}
\Pi^{v} & =\left[a-\left(c_{0}-g\right)-x-x^{*}\right] x-\frac{e}{2} g^{2} \\
\Pi^{* v} & =\left[a-\left(c_{0}^{*}-g^{*}\right)-x-x^{*}\right] x^{*}-\frac{e^{*}}{2} g^{* 2} .
\end{aligned}
$$

\footnotetext{
${ }^{6}$ We exclude the two extreme cases in which $\theta=0$ and $\theta=1$. The case of $\theta=0$ is not interesting because it means no technology spillover. The case of $\theta=1$ is excluded because in general a firm can never be as good as the other firm from which it learns.
} 
Both firms choose the new technology level (marginal cost) first and then compete in terms of output. Since the present game never involves the problem of time inconsistency, we need not solve the game in a backward way; i.e., the solution obtained by solving the game backward is equivalent to the solution derived in the first stage. Thus we assume that the Home firm maximizes (5a) with respect to $x$ and $g$, whereas the Foreign firm (5b) with respect to $x^{*}$ and $g^{*}$, both in a Cournot-Nash fashion. The corresponding first-order conditions for profit maximization $\operatorname{are}^{7}$

$$
\begin{aligned}
x & : \quad a-c_{0}+g-2 x-x^{*}=0 \\
g & : \quad x-e g=0 \\
x^{*} & : \quad a-c_{0}^{*}+g^{*}-x-2 x^{*}=0 \\
g^{*} & : \quad x^{*}-e^{*} g^{*}=0 .
\end{aligned}
$$

This system is solved as follows. From (6b) and (6d), $x=e g$ and $x^{*}=e g^{*}$ follow. Then, substituting these into (6a) and (6c), we get

$$
\begin{aligned}
& a-c_{0}-(2 e-1) g-e^{*} g^{*}=0 \\
& a-c_{0}^{*}-e g-\left(2 e^{*}-1\right) g^{*}=0 .
\end{aligned}
$$

Solving this system for $g$ and $g^{*}$ yields the optimal innovation levels:

$$
\begin{aligned}
g^{v} & =g^{v}\left(e, e^{*}\right)=\frac{\left(e^{*}-1\right)\left(a-c_{0}\right)+e^{*}\left(c_{0}^{*}-c_{0}\right)}{(2 e-1)\left(2 e^{*}-1\right)-e e^{*}} \\
g^{* v} & =g^{* v}\left(e, e^{*}\right)=\frac{(e-1)\left(a-c_{0}^{*}\right)-e\left(c_{0}^{*}-c_{0}\right)}{(2 e-1)\left(2 e^{*}-1\right)-e e^{*}} .
\end{aligned}
$$

\footnotetext{
${ }^{7}$ Throughout the paper, we assume interior equilibria.
} 
Given assumptions 1 and $2, g^{v}>0$ and $g^{* v}>0$. Combining (7), (6b), and (6d), we get the optimal outputs as follows:

$$
\begin{aligned}
x^{v} & =x^{v}\left(e, e^{*}\right)=e\left[\frac{\left(e^{*}-1\right)\left(a-c_{0}\right)+e^{*}\left(c_{0}^{*}-c_{0}\right)}{(2 e-1)\left(2 e^{*}-1\right)-e e^{*}}\right] \\
x^{* v} & =x^{* v}\left(e, e^{*}\right)=e^{*}\left[\frac{(e-1)\left(a-c_{0}^{*}\right)-e\left(c_{0}^{*}-c_{0}\right)}{(2 e-1)\left(2 e^{*}-1\right)-e e^{*}}\right] .
\end{aligned}
$$

Making use of (7) and (8), the profits of the firms as given by (5) reduce to:

$$
\begin{aligned}
\Pi^{v}\left(e, e^{*}\right) & =\frac{e(2 e-1)}{2}\left[\frac{\left(e^{*}-1\right)\left(a-c_{0}\right)+e^{*}\left(c_{0}^{*}-c_{0}\right)}{(2 e-1)\left(2 e^{*}-1\right)-e e^{*}}\right]^{2} \\
\Pi^{* v}\left(e, e^{*}\right) & =\frac{e^{*}\left(2 e^{*}-1\right)}{2}\left[\frac{(e-1)\left(a-c_{0}^{*}\right)-e\left(c_{0}^{*}-c_{0}\right)}{(2 e-1)\left(2 e^{*}-1\right)-e e^{*}}\right]^{2} .
\end{aligned}
$$

The above analysis shows that the outputs, innovation levels, and profits are functions of the costs of innovation, $e$ and $e^{*}$.

Lemma 1. In the present case with both firms innovating, we have

$$
\begin{aligned}
& \frac{\partial g^{v}}{\partial e}<0, \quad \frac{\partial g^{v}}{\partial e^{*}}>0, \quad \frac{\partial g^{* v}}{\partial e}>0, \quad \frac{\partial g^{* v}}{\partial e^{*}}<0 \\
& \frac{\partial x^{v}}{\partial e}<0, \quad \frac{\partial x^{v}}{\partial e^{*}}>0, \quad \frac{\partial x^{* v}}{\partial e}>0, \quad \frac{\partial x^{* v}}{\partial e^{*}}<0 .
\end{aligned}
$$

The proofs of all lemmas, propositions, and corollaries are given in the appendix.

Lemma 2. $\Pi_{e}^{v}<0, \Pi_{e^{*}}^{v}>0, \Pi_{e}^{* v}>0$ and $\Pi_{e^{*}}^{* v}<0 .^{8}$

Lemmas 1 and 2 make it clear why $e$ and $e^{*}$ are interpreted as the cost of innovation: An increase in its value a firm faces discourages the firm's innovation, output, and profit but encourages those of the other firm.

\footnotetext{
${ }^{8}$ Subindices are used to denote partial derivatives.
} 


\section{Case (B): Foreign Firm Imitating}

Denote the profits of the Home and Foreign firms by $\Pi^{m}$ and $\Pi^{* m}$, respectively. Since imitation involves zero cost, the profits of the firms are

$$
\begin{aligned}
\Pi^{m} & =\left[a-\left(c_{0}-g\right)-x-x^{*}\right] x-\frac{e}{2} g^{2} \\
\Pi^{* m} & =\left[a-c_{1}^{* m}-x-x^{*}\right] x^{*} .
\end{aligned}
$$

Maximizing (10a) with respect to $x$ and $g$ and (10b) with respect to $x^{*}$ gives the following optimality conditions

$$
\begin{aligned}
x & : a-c_{0}+g-2 x-x^{*}=0 \\
g & : \quad x-e g=0 \\
x^{*} & : a-c_{1}^{* m}-x-2 x^{*}=0,
\end{aligned}
$$

where $c_{1}^{* m}=c_{0}^{*}-\theta\left(c_{0}^{*}-c_{0}\right)$. Solving this system immediately yields

$$
\begin{aligned}
x^{m} & =x^{m}(e, \theta)=\frac{e\left[a-c_{0}+(1-\theta)\left(c_{0}^{*}-c_{0}\right)\right]}{3 e-2} \\
x^{* m} & =x^{* m}(e, \theta)=\frac{(2 e-1)\left[a-c_{0}^{*}+\theta\left(c_{0}^{*}-c_{0}\right)\right]-e\left(a-c_{0}\right)}{3 e-2} \\
g^{m} & =g^{m}(e, \theta)=\frac{a-c_{0}+(1-\theta)\left(c_{0}^{*}-c_{0}\right)}{3 e-2},
\end{aligned}
$$

where superscript " $m$ " denotes the variables in the present case. The resulting profits of the firms are

$$
\begin{aligned}
\Pi^{m}(e, \theta) & =\frac{e(2 e-1)}{2}\left[\frac{a-c_{0}+(1-\theta)\left(c_{0}^{*}-c_{0}\right)}{3 e-2}\right]^{2} \\
\Pi^{* m}(e, \theta) & =\left\{\frac{(2 e-1)\left[a-c_{0}^{*}+\theta\left(c_{0}^{*}-c_{0}\right)\right]-e\left(a-c_{0}\right)}{3 e-2}\right\}^{2} .
\end{aligned}
$$

The dependence of the outputs, innovation level, and the profits of the firms are derived as follows. 
Lemma 3. In the present case with the Foreign firm imitating, we have

$$
\begin{aligned}
& \frac{\partial x^{m}}{\partial e}<0, \quad \frac{\partial x^{m}}{\partial \theta}<0, \quad \frac{\partial x^{* m}}{\partial e}>0, \quad \frac{\partial x^{* m}}{\partial \theta}>0 \\
& \frac{\partial g^{m}}{\partial e}<0, \quad \frac{\partial g^{m}}{\partial \theta}<0 .
\end{aligned}
$$

Lemma 4. $\Pi_{e}^{m}<0, \Pi_{\theta}^{m}<0, \Pi_{e}^{* m}>0$ and $\Pi_{\theta}^{* m}>0$.

As in the case of innovation by the less efficient firm, an increase in the cost of innovation faced by the advanced firm is detrimental to the firm's innovation, output, and profit but is good for the other firm. Not surprisingly, an increase in the degree of imitation, $\theta$, has similar effects because it tends to help the less efficient firm but hurt the advanced firm.

\section{Surpassing and Catching Up}

Before we explain how the foreign firm chooses between innovation and imitation, we want to derive more properties of the two cases. In particular, we want to examine how in each of the cases surpassing or catching up is possible.

Definition (Surpassing). Surpassing by the Foreign firm occurs if and only if $c_{1}>c_{1}^{*}$.

Definition (Catching Up). Catching up by the Foreign firm occurs if and only if $c_{0}^{*}-c_{0}>c_{1}^{*}-c_{1}>0$.

In other words, the Foreign firm is said to have surpassed the Home firm in terms of technology if its new marginal cost is lower than that of the Home firm. The Foreign firm is said to be catching up if it is closing the 
technology gap between the two firms, but the Home firm still has a more advanced technology. We want to derive conditions under which surpassing or catching up is possible.

\subsection{Case (A)}

We now examine the conditions for surpassing and catching-up in case (A), in which the Foreign firm innovates (so does the Home firm).

Proposition 1. Given Assumption 2, if the Foreign firm chooses to innovate, it will surpass the Home firm if and only if

$$
e>\frac{e^{*}\left(a-c_{0}^{*}\right)}{\left(a-c_{0}\right)-3 e^{*}\left(c_{0}^{*}-c_{0}\right)} .
$$

Corollary 1. If the Foreign firm has a cost of innovation not less than that of the Home firm, $e^{*} \geq e$, then surpassing is not possible with both firms innovating.

What the proposition and condition (14) mean is that if the Home firm's cost of innovation is sufficiently higher than that of the Foreign firm, the Foreign firm will choose a new marginal cost lower than what the Home firm chooses.

[Figure 1 approximately here.]

Surpassing can be illustrated graphically in Figure 1. Curve SP represents the following equation:

$$
e=\frac{e^{*}\left(a-c_{0}^{*}\right)}{\left(a-c_{0}\right)-3 e^{*}\left(c_{0}^{*}-c_{0}\right)} .
$$

It passes through the origin. The slope of curve SP is equal to

$$
\left.\frac{\mathrm{d} e^{*}}{\mathrm{~d} e}\right|_{\mathrm{SP}}=\frac{\left[a-c_{0}-3 e^{*}\left(c_{0}^{*}-c_{0}\right)\right]^{2}}{\left(a-c_{0}\right)\left(a-c_{0}^{*}\right)}>0 .
$$


When $e^{*} \rightarrow 0$, the slope of the curve is greater than unity, implying that curve $\mathrm{SP}$ is above the $45^{\circ}$ line in the small region near the origin (except at the origin). Equation (16) shows that the slope is monotonically decreasing with $e^{*}$. Curve SP cuts the $45^{\circ}$ line when $e=e^{*}$, or, from (15), when $e=e^{*}=1 / 3$. For $e>1 / 3$, curve $\mathrm{SP}$ is entirely below the $45^{\circ}$ line. For $e>z$ (Assumption 2 ), surpassing occurs in the region on the right hand side of (below) curve SP.

We now turn to catching up.

Proposition 2. In the present case in which both sides choose to innovate, when given assumption 1, catching up occurs if and only if

$$
e>\frac{e^{*}\left(a-c_{0}\right)+\left(e^{*}-1\right)\left(c_{0}^{*}-c_{0}\right)}{a-2 c_{0}^{*}+c_{0}} .
$$

Corollary 2. If $e^{*} \geq e$, catching up is not possible.

Catching up can be illustrated graphically. In Figure 1, curve CV represents equation

$$
e=\frac{e^{*}\left(a-c_{0}\right)+\left(e^{*}-1\right)\left(c_{0}^{*}-c_{0}\right)}{a-2 c_{0}^{*}+c_{0}} .
$$

The slope of curve CV is equal to

$$
\left.\frac{\mathrm{d} e^{*}}{\mathrm{~d} e}\right|_{\mathrm{CV}}=\frac{a-2 c_{0}^{*}+c_{0}}{a-2 c_{0}+c_{0}^{*}}>0 .
$$

Equation (19) shows that the slope of curve CV is constant and less than one. From (18), we see that curve CV cuts the horizontal axis at a point at which $e=-\left(c_{0}^{*}-c_{0}\right) /\left(a-2 c_{0}^{*}+c_{0}\right)$, and cuts the $45^{\circ}$ line when $e=e^{*}=1 / 3$.

It is interesting to compare curve $\mathrm{SP}$ and curve $\mathrm{CV}$, as both of them are positively sloped. 
Lemma 5. Curves SP and CV intersect at two points, A $\left(e=e^{*}=1 / 3\right)$ and $\mathrm{B}\left(e=e^{*}=\sigma\right.$, where $\left.\sigma=\left(a-c_{0}\right) /\left(a-2 c_{0}+c_{0}^{*}\right)<1\right)$. For $e \in[0,1 / 3)$ and $e \in(\sigma, \infty)$, curve $\mathrm{CV}$ is above curve SP. For $e \in(1 / 3, \sigma)$, curve CV is below curve SP.

The above results are shown in Figure 1. Points A and B are the points of intersection between curve SP and curve CV. Since we focus on the area in which $e>z$, we can conclude that in this relevant region, curve SP is below and on the right hand side of curve CV.

\subsection{Case (B)}

Let us now turn to the case in which the Foreign firm chooses to imitate while the Home firm innovates. We first note that imitation will never make the Foreign firm as good as the Home firm before Home firm's innovation. In other words, if the Foreign firm chooses to imitate, surpassing can never happen. This result is formally stated and proved below:

Proposition 3. In case (B) with the Foreign firm imitating, surpassing is not possible.

Proposition 3 is quite intuitive. Surpassing equation (4) implies that at best the Foreign firm can improve its technology to the initial technology level of the Home firm. ${ }^{9}$

Proposition 4. In case (B) with the Foreign firm imitating, catching up occurs if and only if

$$
e>\frac{a-c_{0}+(\theta+1)\left(c_{0}^{*}-c_{0}\right)}{3 \theta\left(c_{0}^{*}-c_{0}\right)} .
$$

\footnotetext{
${ }^{9}$ We do not consider the unrealistic case in which $\theta>1$.
} 
Proposition 4 means that by imitating, the Foreign firm may make a bigger technology improvement than the Home firm does. This occurs if the Home firm's cost of innovation is high as compared with the degree of imitation. Catching up with the Foreign firm imitating can also be illustrated graphically. Let us consider the following condition

$$
e=\frac{a-c_{0}+(\theta+1)\left(c_{0}^{*}-c_{0}\right)}{3 \theta\left(c_{0}^{*}-c_{0}\right)},
$$

which gives the threshold values of $e$ and $\theta$ with which the technology gap between the two firms remains constant. The condition, when given a value

of $\theta$ can be represented by a vertical line in the $e-e^{*}$ space similar to Figure 1 (not shown). The space to the right of the line represents values of $e$ (when given $\theta$ ) that lead to catching up.

\section{Choosing between Innovation and Imita- tion}

So far, we have focused the analysis on each of the two cases, assuming that the Foreign firm either innovates or imitates. We now explain how the firm will choose between these two actions.

Since the Foreign firm tries to maximize its profit, it innovates if and only if

$$
\Pi^{* v}\left(e, e^{*}\right)>\Pi^{* m}(e, \theta) .
$$

To see the choice for the Foreign firm, let us consider the following condition:

$$
\Pi^{* v}\left(e, e^{*}\right)=\Pi^{* m}(e, \theta) .
$$

[Figure 2 approximately here.] 
Based (22), (23) represents the combinations of $e, e^{*}$, and $\theta$ that will make the Foreign firm indifferent between innovation and imitation. These combinations, when given $\theta$, can be represented by the indifference locus, labeled IL, in Figure 2. Totally differentiate both sides of (23) to give

$$
\Pi_{e}^{* v} \mathrm{~d} e+\Pi_{e^{*}}^{* v} \mathrm{~d} e^{*}=\Pi_{e}^{* m} \mathrm{~d} e+\Pi_{\theta}^{* m} \mathrm{~d} \theta .
$$

From Lemmas 2 and $4, \Pi_{e^{*}}^{* v}<0$, while $\Pi_{e}^{* m}, \Pi_{e}^{* v}$, and $\Pi_{\theta}^{* m}$ are both positive. When given the value of $\theta,(24)$ is rearranged to give the slope of curve IL

$$
\left.\frac{\mathrm{d} e^{*}}{\mathrm{~d} e}\right|_{\mathrm{IL}}=\frac{\Pi_{e}^{* m}-\Pi_{e}^{* v}}{\Pi_{e^{*}}^{* v}} .
$$

The sign of the slope is ambiguous. Thus curve IL is positively sloped if and only if $\Pi_{e}^{* m}<\Pi_{e}^{* v}$, i.e., if and only if a rise in $e$ will help the Foreign firm more when it imitates than when it innovates. This case is shown in Figure 2. The area on the right (left) hand side of curve IL represents the values of $e$ and $e^{*}$ that will lead to innovation (imitation) by the Foreign firm.

Since $\Pi_{\theta}^{* m}>0$, an increase in $\theta$ will shift curve IL down and to the right, say, I'L'. This means that the Foreign firm will more likely choose to imitate. For example, point Q is on curve IL, meaning that the Foreign firm is indifferent between imitation and innovation. If there is a rise in $\theta$, the curve shifts to $\mathrm{I}^{\prime} \mathrm{L}^{\prime}$. Point $\mathrm{Q}$ now becomes a point above the curve, implying that the Foreign firm now prefers to imitate.

[Figure 3 approximately here.]

We can now add in curves SP and CV to the diagram. See Figure 3. By Lemma 5, for $e>z$, curve SP is below and to the right of curve CV. We can add in line CM, which gives the values of $e$ (when given $\theta$ ) that will help the Foreign firm catch up when it chooses imitation. We can now identify 
the following regions in the diagram (Innovation or imitation refers to the decision of the Foreign firm, as the Home firm always innovates.):

- V1: innovation with no catching up or surpassing;

- V2: innovation with catching up but no surpassing;

- V3: innovation with surpassing;

- M1: imitation with no catching up;

- M2: imitation with catching up.

So far we have been focusing on the choice of the Foreign firm and its profits. Now let us examine how the profit of the Home firm may be different in different cases. In particular, we want to raise and answer one interesting question: Suppose that we do not endogenize the decision of the Foreign firm, as many papers in the literature do, how would the profit of the Home firm be affected? To see this question more clearly, consider the values of $\left(e, e^{*}, \theta\right)$ that are represented by point $\mathrm{R}$ in Figure 2. At this point, the Foreign firm will choose to innovate because $\Pi^{* v}\left(e, e^{*}\right)>\Pi^{* m}(e, \theta)$. If it does, the Home firm's profit is $\Pi^{v}\left(e, e^{*}\right)$. However, if we assume that the Foreign firm imitates, the Home firm's profit will be $\Pi^{m}(e, \theta)$. How can these two profits of the Home firm be compared? In other words, if one follows the practice of many papers in the literature and assumes that the Foreign firm imitates, then what kind of error may one commit?

Before we answer the above questions, let us first present the following 2 lemmas: 
Lemma 6. If the Home firm always chooses its output and level of innovation optimally, its profit is negatively dependent on the Foreign firm's output but independent of whether the Foreign firm innovates or imitates.

This lemma is just a simple application of the Envelope Theorem.

Lemma 7. If $\Pi^{* v}\left(e, e^{*}\right)>\Pi^{* m}(e, \theta)$, then $g^{* v}>\theta\left(c_{0}^{*}-c_{0}\right)$ and $c_{1}^{* v}<c_{1}^{* m}$.

Lemmas 6 and 7 are used to prove the following proposition, which answers the questions raised earlier.

Proposition 5. If $\Pi^{* v}\left(e, e^{*}\right)>\Pi^{* m}(e, \theta)$, then $\Pi^{v}\left(e, e^{*}\right)<\Pi^{m}(e, \theta)$.

The proposition implies that if the Foreign firm prefers to innovate but is allowed to imitate only, its profit will drop while the profit of the Home firm will rise. In other words, in the innovation-imitation models, if the Foreign firm in fact prefers to innovate but is assumed to imitate, the profit of the Foreign firm could be underestimated but that of the Home firm be overestimated.

\section{Concluding Remarks}

Using a simple model of international rivalry, we analyzed how two firms compete in terms of technology and output. We derived conditions for the less efficient firm to choose between innovation and imitation, and also conditions under which the less efficient firm is able to catch up or to surpass the technology of the other firm.

Endogenizing the innovation/imitation decision of the less efficient firm allows us to examine the potential risk of the artificial assumption that the less efficient firm always imitates. We argued that if the less efficient firm 
would choose to innovate, if allowed to, then assuming that it imitates will tend to underestimate its profit but overestimate the profit of the other firm.

In the present paper, we restricted our analysis to a static model in order to get more insight and results. It would be interesting to examine some dynamic issues such as switching between innovation and imitation over time using a dynamic model, as Shimomura and Wong (2001) do. Another approach to analyzing the issues of growth and innovation/imitation switching is to combine the present framework with a differential game of duopoly in which both of the two firms have two alternatives: to innovate and to imitate. ${ }^{10}$ The latter could be a topic of future research.

\footnotetext{
${ }^{10}$ See, for example, Fershtman and Kamien (1987) and Tsutsui and Mino (1990) for recent work of analysis using differential game models of duopoly.
} 


\section{Appendix}

Proofs of Lemmas and Propositions Stated in this Paper

Proof of Lemma 1. Differentiating (7a) and (8a) with respect to $e$ and $e^{*}$, we get

$$
\begin{aligned}
\frac{\partial g^{v}}{\partial e} & =\frac{-\left(3 e^{*}-2\right)\left[\left(e^{*}-1\right)\left(a-c_{0}\right)+e^{*}\left(c_{0}^{*}-c_{0}\right)\right]}{\left[(2 e-1)\left(2 e^{*}-1\right)-e e^{*}\right]^{2}}<0 \\
\frac{\partial g^{v}}{\partial e^{*}} & =\frac{(e-1)\left(a-c_{0}^{*}\right)-e\left(c_{0}^{*}-c_{0}\right)}{\left[(2 e-1)\left(2 e^{*}-1\right)-e e^{*}\right]^{2}}>0 \\
\frac{\partial x^{v}}{\partial e} & =\frac{-\left(2 e^{*}-1\right)\left[\left(e^{*}-1\right)\left(a-c_{0}\right)+e^{*}\left(c_{0}^{*}-c_{0}\right)\right]}{\left[(2 e-1)\left(2 e^{*}-1\right)-e e^{*}\right]^{2}}<0 \\
\frac{\partial x^{v}}{\partial e^{*}} & =e \frac{\partial g^{v}}{\partial e^{*}}>0 .
\end{aligned}
$$

The effects of $e$ and $e^{*}$ on $g^{* v}$ and $x^{* v}$ can be obtained in a symmetric way.

Proof of Lemma 2. Differentiating (9a) and (9b) with respect to $e$ and $e^{*}$ respectively yields

$$
\begin{aligned}
\Pi_{e}^{v} & =-\frac{1}{2}\left[\frac{\psi^{*}}{(2 e-1)\left(2 e^{*}-1\right)-e e^{*}}\right]^{2}<0 \\
\Pi_{e^{*}}^{v} & =\frac{\psi \psi^{*} e(2 e-1)}{\left[(2 e-1)\left(2 e^{*}-1\right)-e e^{*}\right]^{3}}>0 \\
\Pi_{e}^{* v} & =\frac{\psi \psi^{*} e^{*}\left(2 e^{*}-1\right)}{\left[(2 e-1)\left(2 e^{*}-1\right)-e e^{*}\right]^{3}}>0 \\
\Pi_{e^{*}}^{* v} & =-\frac{1}{2}\left[\frac{\psi}{(2 e-1)\left(2 e^{*}-1\right)-e e^{*}}\right]^{2}<0,
\end{aligned}
$$

where the assumption that both $g^{v}$ and $g^{* v}$ are positive has been used and $\psi=(e-1)\left(a-c_{0}^{*}\right)-e\left(c_{0}^{*}-c_{0}\right)$ and $\psi^{*}=\left(e^{*}-1\right)\left(a-c_{0}\right)+e^{*}\left(c_{0}^{*}-c_{0}\right)$. 
Proof of Lemma 3. The response of $g^{m}$ on $e$ and $\theta$, and $\partial x^{m} / \partial \theta$ are trivially obtained, while the other results are derived as

$$
\begin{aligned}
\frac{\partial x^{m}}{\partial e} & =\frac{-2\left[a-c_{0}+(1-\theta)\left(c_{0}^{*}-c_{0}\right)\right]}{(3 e-2)^{2}}<0 \\
\frac{\partial x^{* m}}{\partial e} & =\frac{a-c_{0}+(1-\theta)\left(c_{0}^{*}-c_{0}\right)}{(3 e-2)^{2}}>0 \\
\frac{\partial x^{* m}}{\partial \theta} & =\frac{(2 e-1)\left(c_{0}^{*}-c_{0}\right)}{3 e-2}>0 .
\end{aligned}
$$

This gives Lemma 3.

Proof of Lemma 4. Differentiating (13a) and (13b) with respect to $e$ and $\theta$, we have

$$
\begin{aligned}
\Pi_{e}^{m} & =\frac{(2-5 e) \zeta^{2}}{2(3 e-2)^{3}}<0 \\
\Pi_{\theta}^{m} & =\frac{-e(2 e-1) \zeta\left(c_{0}^{*}-c_{0}\right)}{3 e-2}<0 \\
\Pi_{e}^{* m} & =\frac{2 \zeta\left[(2 e-1) \zeta^{*}-e\left(a-c_{0}\right)\right]}{(3 e-2)^{3}}>0 \\
\Pi_{\theta}^{* m} & =\frac{2(2 e-1)\left(c_{0}^{*}-c_{0}\right)\left[\zeta^{*}(2 e-1)-e\left(a-c_{0}\right)\right]}{(3 e-2)^{2}}>0,
\end{aligned}
$$

where $\zeta=a-c_{0}+(1-\theta)\left(c_{0}^{*}-c_{0}\right)$ and $\zeta^{*}=a-c_{0}^{*}+\theta\left(c_{0}^{*}-c_{0}\right)$. The signs of the partial derivatives depend on the assumption that the outputs and innovation level are positive.

Proof of Lemma 5. Equations (15) and (18) imply that the horizontal gap between curves $\mathrm{CV}$ and $\mathrm{SP}$ is equal to

$$
\begin{aligned}
& \frac{e^{*}\left(a-c_{0}\right)+\left(e^{*}-1\right)\left(c_{0}^{*}-c_{0}\right)}{a-c_{0}^{*}-\left(c_{0}^{*}-c_{0}\right)}-\frac{e^{*}\left(a-c_{0}^{*}\right)}{a-c_{0}-3 e^{*}\left(c_{0}^{*}-c_{0}\right)} \\
= & \frac{-\left(3 e^{*}-1\right)\left(c_{0}^{*}-c_{0}\right)\left[\left(e^{*}-1\right)\left(a-c_{0}\right)+e^{*}\left(c_{0}^{*}-c_{0}\right)\right]}{\left[a-c_{0}^{*}-\left(c_{0}^{*}-c_{0}\right)\right]\left[a-c_{0}-3 e^{*}\left(c_{0}^{*}-c_{0}\right)\right]}
\end{aligned}
$$


Setting the numerator in (19) to zero gives two roots: $e^{*}=1 / 3$ and $e^{*}=\sigma<$ 1. Comparison between (15) and (18) implies that curve CV is above curve SP when $e^{*}<1 / 3$ and when $e^{*}>\sigma$. In between these two points, curve CV is below curve SP.

Proof of Lemma 6. We first note that equation (5a) is identical to equation (10a), meaning that the Home firm's profit function is independent of whether the Foreign firm innovates or imitates. Its decision depends only on what the Foreign firm produces. Its profit function can be written as $\Pi=\hat{\Pi}\left(x, g, x^{*}\right)$. If the firm always chooses $x$ and $g$ optimally, then

$$
\frac{\mathrm{d} \Pi}{\mathrm{d} x^{*}}=\frac{\partial \Pi}{\partial x} \frac{\mathrm{d} x}{\mathrm{~d} x^{*}}+\frac{\partial \Pi}{\partial g} \frac{\mathrm{d} g}{\mathrm{~d} x^{*}}+\frac{\partial \Pi}{\partial x^{*}}=-x<0 .
$$

This proves the lemma.

Proof of Lemma \%. Suppose that $\Pi^{* v}\left(e, e^{*}\right)>\Pi^{* m}(e, \theta)$. If $g^{* v} \leq \theta\left(c_{0}^{*}-c_{0}\right)$, then innovation can never be a good choice because the Foreign firm can choose imitation instead, after paying nothing and getting a bigger or equal technology improvement. So we must have $g^{* v}>\theta\left(c_{0}^{*}-c_{0}\right)$, which implies that $c_{1}^{* v}<c_{1}^{* m}$.

Proof of Proposition 1. In case (A), with both firms innovating, the new gap between the firms' marginal costs is

$$
\begin{aligned}
c_{1}^{* v}-c_{1}^{v} & =c_{0}^{*}-g^{* v}-c_{0}+g^{v} \\
& =\frac{e\left(3 e^{*}-1\right)\left(c_{0}^{*}-c_{0}\right)+\left(e^{*}-e\right)\left(a-c_{0}^{*}\right)}{(2 e-1)\left(2 e^{*}-1\right)-e e^{*}},
\end{aligned}
$$

which in general can be both positive and negative. Given Assumption 2, the numerator in (27) is positive. Thus, $c_{1}^{* v}-c_{1}^{v}<0$ if and only if the numerator in (27) is negative, or if and only if

$$
-e\left[a-c_{0}-3 e^{*}\left(c_{0}^{*}-c_{0}\right)\right]+e^{*}\left(a-c_{0}^{*}\right)<0 .
$$


Condition (28) is equivalent to (14). ${ }^{11}$

Proof of Proposition 2. To determine whether catching up exists, note that

$$
\begin{aligned}
\left(c_{0}^{*}-c_{0}\right)-\left(c_{1}^{* v}-c_{1}^{v}\right) & \equiv c_{0}^{*}-c_{0}-\left(c_{0}^{*}-g^{* v}-c_{0}+g^{v}\right) \\
& =g^{* v}-g^{v} \\
& =\frac{e\left(a-2 c_{0}^{*}+c_{0}\right)-e^{*}\left(a-c_{0}\right)-\left(e^{*}-1\right)\left(c_{0}^{*}-c_{0}\right)}{(2 e-1)\left(2 e^{*}-1\right)-e e^{*}}
\end{aligned}
$$

From the definition, we can see that catching up exists if and only if the numerator is positive. Rearranging the terms will give the proposition.

Proof of Proposition 3. We note that

$$
\begin{aligned}
c_{1}^{* m}-c_{1}^{m} & =c_{0}^{*}-\theta\left(c_{0}^{*}-c_{0}\right)-c_{0}+g^{m} \\
& =\frac{\left(a-c_{0}\right)+(3 e-1)(1-\theta)\left(c_{0}^{*}-c_{0}\right)}{3 e-2}>0 .
\end{aligned}
$$

This proves the proposition.

Proof of Proposition 4. With the Foreign firm imitating, the change in the gap between the marginal costs of the firms is given by

$$
\begin{aligned}
\left(c_{0}^{*}-c_{0}\right)-\left(c_{1}^{* m}-c_{1}^{m}\right) & \equiv c_{0}^{*}-c_{0}-\left[c_{0}^{*}-\theta\left(c_{0}^{*}-c_{0}\right)-c_{0}+g^{m}\right] \\
& =\theta\left(c_{0}^{*}-c_{0}\right)-g^{m} \\
& =\frac{\theta(3 e-2)\left(c_{0}^{*}-c_{0}\right)-\left(a-c_{0}\right)-(1-\theta)\left(c_{0}^{*}-c_{0}\right)}{3 e-2} .
\end{aligned}
$$

The change in the gap is positive if and only if the numerator is positive. Rearranging the terms will give the proposition.

Proof of Proposition 5. Note first that the two reaction functions given by (6a) and (6b), or (11a) and (11b), of the Home firm depend on $x^{*}$ but not on

\footnotetext{
${ }^{11}$ In deriving (28), we have assumed that $a-c_{0}-3 e^{*}\left(c_{0}^{*}-c_{0}\right)>0$.
} 
whether the Foreign firm innovates or imitates. Substituting (6b) into (6a) (or (11b) into (11a)), we get a function similar to the usual reaction function of a firm in a duopoly model. If $\Pi^{* v}\left(e, e^{*}\right)>\Pi^{* m}(e, \theta)$, then by Lemma 7 , $c_{1}^{* v}<c_{1}^{* m}$. This means that if the Foreign firm chooses to innovate but if it is allowed to imitate only, its new marginal cost will be higher, no matter what the Home firm chooses. It is well known in the regular duopoly model that a rise in the marginal cost of one of the firms will cause it to lower its output. By lemma 6, the profit of the Home firm will be higher.

Proof of Corollary 1. If $e^{*} \geq e$, then the numerator in (27) is positive, implying that $c_{1}^{* v}>c_{1}^{v}$.

Proof of Corollary 2. If $e^{*} \geq e$, the right hand side of (17) can be rearranged to give

$$
\begin{aligned}
\frac{e^{*}\left(a-c_{0}\right)+\left(e^{*}-1\right)\left(c_{0}^{*}-c_{0}\right)}{a-2 c_{0}^{*}+c_{0}} & =e^{*}+\frac{\left(3 e^{*}-1\right)\left(c_{0}^{*}-c_{0}\right)}{a-2 c_{0}^{*}+c_{0}} \\
& >e^{*},
\end{aligned}
$$

violating condition (17), implying that catching up is not possible. 


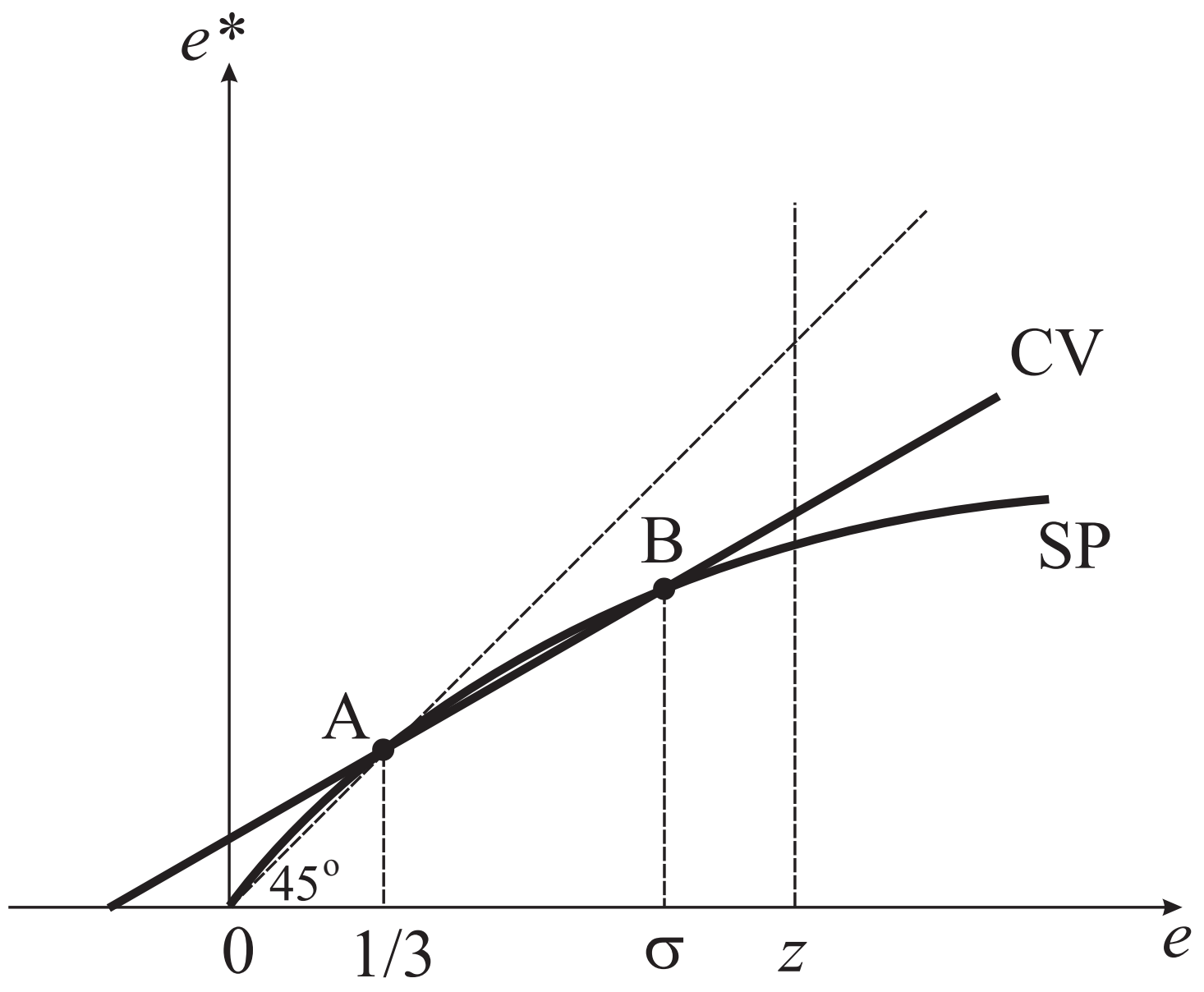

Figure 1:

Curves SP and CV 


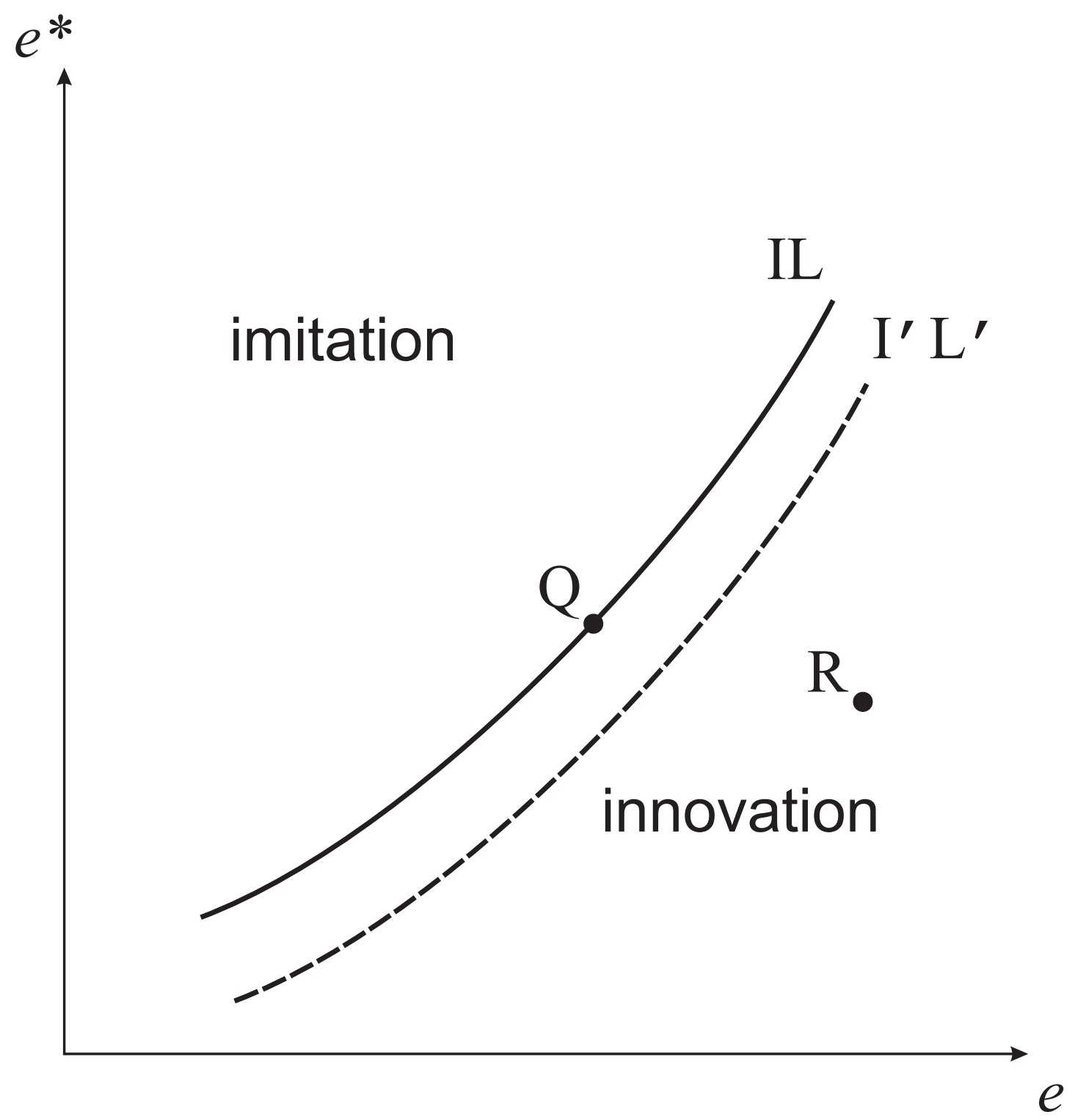

Figure 2:

Curve IL 


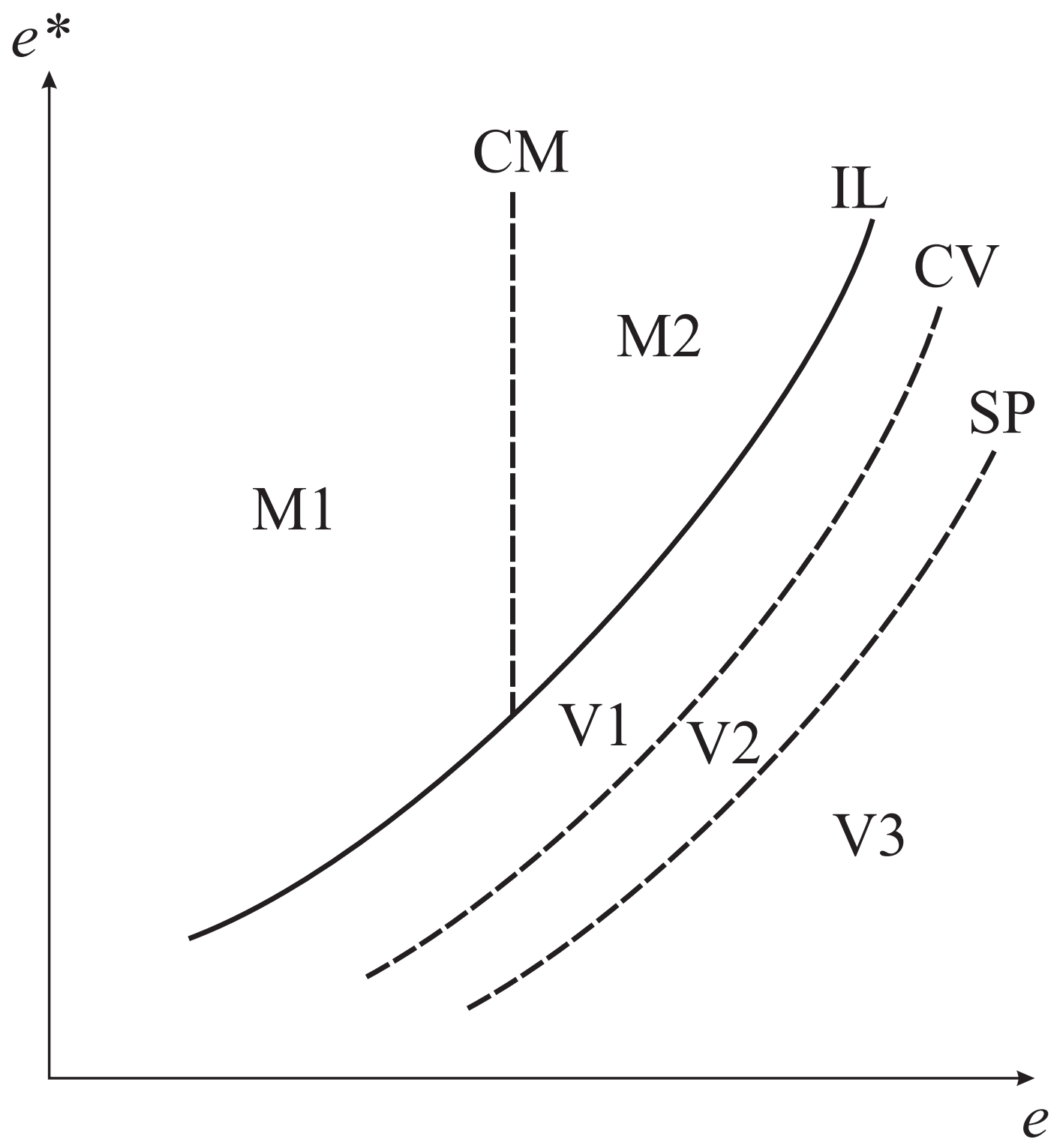

Figure 3:

Innovation and Imitation 


\section{References}

[1] Bhagwati, J. N. (2004) In Defense of Globalization, New York: Oxford University Press.

[2] Bagwell, K. and R. W. Staiger (1992) 'The Sensitivity of Strategic and Corrective R\&D Policy in Battles for Monopoly', International Economic Review, 33: 795-816.

[3] Bagwell, K. and R. W. Staiger (1994) 'The Sensitivity of Strategic and Corrective R\&D Policy in Oligopolistic Industries', Journal of International Economics, 36: 133-150.

[4] Dinopoulos, E., A. Gungoraydinoglu and C. Syropoulos (2006) 'Parent Protection and Global Schumpeterian Growth', in this volume.

[5] Dinopoulos, E. and C. Syropoulos (1998) 'International Diffusion and Appropriatability of Technological Expertise', in Baye, M. R. (ed.), Advances in Applied Microeconomics, Vol. 7, Amsterdam: Elsevier Science, $115-137$.

[6] Fershtman, C. and M. I. Kamien (1987) 'Dynamic Duopolistic Competition with Sticky Prices', Econometrica, 55: 1151-1164.

[7] Grossman, G. M. and E. Helpman (1991), Innovation and Growth in the Global Economy, Cambridge, MA: MIT Press.

[8] Helpman, E. (1993) 'Innovation, Imitation, and Intellectual Property Rights', Econometrica, 61: 1247-1280. 
[9] Liao, P. and K. Wong (2004) 'R\&D Subsidy, Intellectual Property Rights Protection, and North-South Trade: How Good Is the TRIPS Agreement?', mimeo., University of Washington.

[10] Mondal, D. and M. R. Gupta (2006) 'Innovation, Imitation, and Intellectual Property Rights: A Note on Helpman's Model', Journal of Economics, 87: 29-53.

[11] Segerstrom, P. S. (1991) 'Innovation, Imitation, and Economic Growth', Journal of Political Economy, 99: 807-27.

[12] Shimomura, K. and K. Wong (2001) 'Technology Adoption and Trade Policies', mimeo., University of Washington.

[13] Tsutsui, S. and K. Mino (1990) 'Nonlinear Strategies in a Dynamic Duopolistic Competition with Sticky Prices', Journal of Economic Theory, 52: 136-161. 